\title{
Upper Gastrointestinal Symptoms Are More Frequent in Female than Male Young Healthy Japanese Volunteers as Evaluated by Questionnaire
}

\author{
Hiroharu Kawakubo, ${ }^{1}$ Yuichiro Tanaka, ${ }^{1}$ Nanae Tsuruoka, ${ }^{1}$ Megumi Hara, ${ }^{2}$ Koji Yamamoto, ${ }^{1}$ Hidenori Hidaka, ${ }^{1}$ Yasuhisa Sakata, \\ Ryo Shimoda, ${ }^{1}$ Ryuichi Iwakiri, ${ }^{1}$ Motoyasu Kusano, ${ }^{3}$ and Kazuma Fujimoto ${ }^{1 *}$ \\ Departments of ${ }^{1}$ Internal Medicine and Gastrointestinal Endoscopy, and ${ }^{2}$ Preventive Medicine, Saga Medical School, Saga, Japan; and \\ ${ }^{3}$ Department of Endoscopy and Endoscopic Surgery, Gunma University Hospital, Gunma, Japan
}

\section{Background/Aims}

Upper gastrointestinal symptoms are more frequent and severe in female than in male outpatients in Japan. This study compared the upper gastrointestinal symptoms between healthy male and female young adult volunteers using a questionnaire.

\section{Methods}

In total, 581 third-grade medical students at Saga Medical School aged 22 to 30 years underwent upper gastrointestinal endoscopy and completed a questionnaire (frequency scale for symptoms of gastroesophageal reflux disease) from 2007 to 2013. Of these 581 students, 298 who were negative for Helicobacter pylori infection and had no particular lesions on endoscopic examination were enrolled in the present evaluation. A symptom was defined as positive when the subject evaluated the frequency of the symptom as sometimes, often, or always.

\section{Results}

The subjects comprised of 163 males (average age, 23.7 years) and 135 females (average age, 23.1 years). Upper gastrointestinal symptoms were more frequent in the females (75 of 135, 55.6\%) than males (69 of 163,42.3\%; $P<0.05$ ), with a high score for 4 symptoms (bloated stomach, heavy feeling in the stomach after meals, subconscious rubbing of the chest with the hand, and feeling of fullness while eating meals). Of the 144 subjects (69 males and 75 females) who complained of these symptoms, the females complained of dysmotility symptoms more often than did the males, but this was not true for reflux symptoms.

\section{Conclusions}

This study suggests that females develop upper gastrointestinal symptoms more frequently than do males among the young healthy Japanese population.

(J Neurogastroenterol Motil 2016;22:248-253)

\section{Key Words}

Dyspepsia; Endoscopy; Esophagitis; Gastroesophageal reflux; Gastrointestinal motility

Received: August 31, 2015 Revised: December 14, 2015 Accepted: December 22, 2015

(.) This is an Open Access article distributed under the terms of the Creative Commons Attribution Non-Commercial License (http://creativecommons. org/licenses/by-nc/4.0) which permits unrestricted non-commercial use, distribution, and reproduction in any medium, provided the original work is properly cited.

${ }^{*}$ Correspondence: Kazuma Fujimoto, MD Department of Internal Medicine and Gastrointestinal Endoscopy, Saga Medical School, 5-1-1 Nabeshima, Saga 849-8501, Japan Tel: +81-952-31-6511, Fax: +81-952-34-2017, E-mail: fujimotk@cc.saga-u.ac.jp 


\section{Introduction}

In the 2013 annual survey on public health conducted by the Ministry of Health, Labour and Welfare of Japan, 27.7\% of males and $31.2 \%$ of females had some type of clinical symptoms, indicating that females tended to complain of more clinical symptoms than males in all generations over 20 years of age in Japan. ${ }^{1}$ Previous reports in Japan and Western countries revealed that functional dyspepsia (FD) with abdominal symptoms, including epigastric pain and postprandial fullness, was more common in females than males, and responses to medical treatment were poorer in females than males. ${ }^{2,3}$ However, several other studies reported that the severity and frequency of clinical symptoms of FD were not different between the 2 sexes. ${ }^{4,5}$ These discrepancies might be due to the unclear pathophysiology of FD, and various risk factors for the development of FD. ${ }^{6}$ Additionally, it is possible that there are sex-related differences in the development of upper gastrointestinal symptoms.

This study aimed to clarify whether females might be more likely than males to complain of upper gastrointestinal tract symptoms among young, healthy Japanese subjects without FD. Using the frequency scale for symptoms of gastrointestinal reflux disease (FSSG) questionnaire, ${ }^{7}$ upper gastrointestinal symptoms were examined in young healthy subjects with no particular lesions on upper gastrointestinal endoscopy and without Helicobacter pylori infection.

\section{Materials and Methods}

The present study was approved by the ethics committee of Saga Medical School (October 9, 2014) and was performed at Saga Medical School. Overall, 581 third-grade medical students (males/ females: 322/259) at Saga Medical School participated in this study from 2007 to 2013 with informed consent. The mean \pm standard deviation age was $23.4 \pm 1.5$ years (range, 22-30 years).

All participants underwent upper gastrointestinal endoscopy and the FSSG questionnaire regarding the upper gastrointestinal symptoms within 1 month before endoscopy. Upper gastrointestinal endoscopy was performed by experienced endoscopists on the Japanese Board of Gastrointestinal Endoscopy. H. pylori infection was checked by urinary antibody-coated bacteria tests. In total, 298 subjects who were negative for $H$. pylori infection and had no particular lesions on endoscopic examination were enrolled in the present evaluation. In addition, the upper gastrointestinal symptoms in the male subjects with endoscopic esophagitis (grade A, B, or C in the Los Angeles classification ${ }^{8}$ ) as evaluated by the FSSG were compared with those of male subjects without endoscopic findings and FSSG.

As indicated in Figure 1, the FSSG comprises of 12 questions (7 acid reflux symptoms and 5 dysmotility symptoms). Each symptom was assigned a score (never $=0$, occasionally [30\%] $=1$, sometimes $[50 \%]=2$, often $[70 \%]=3$, and always $[100 \%]=4)$. A

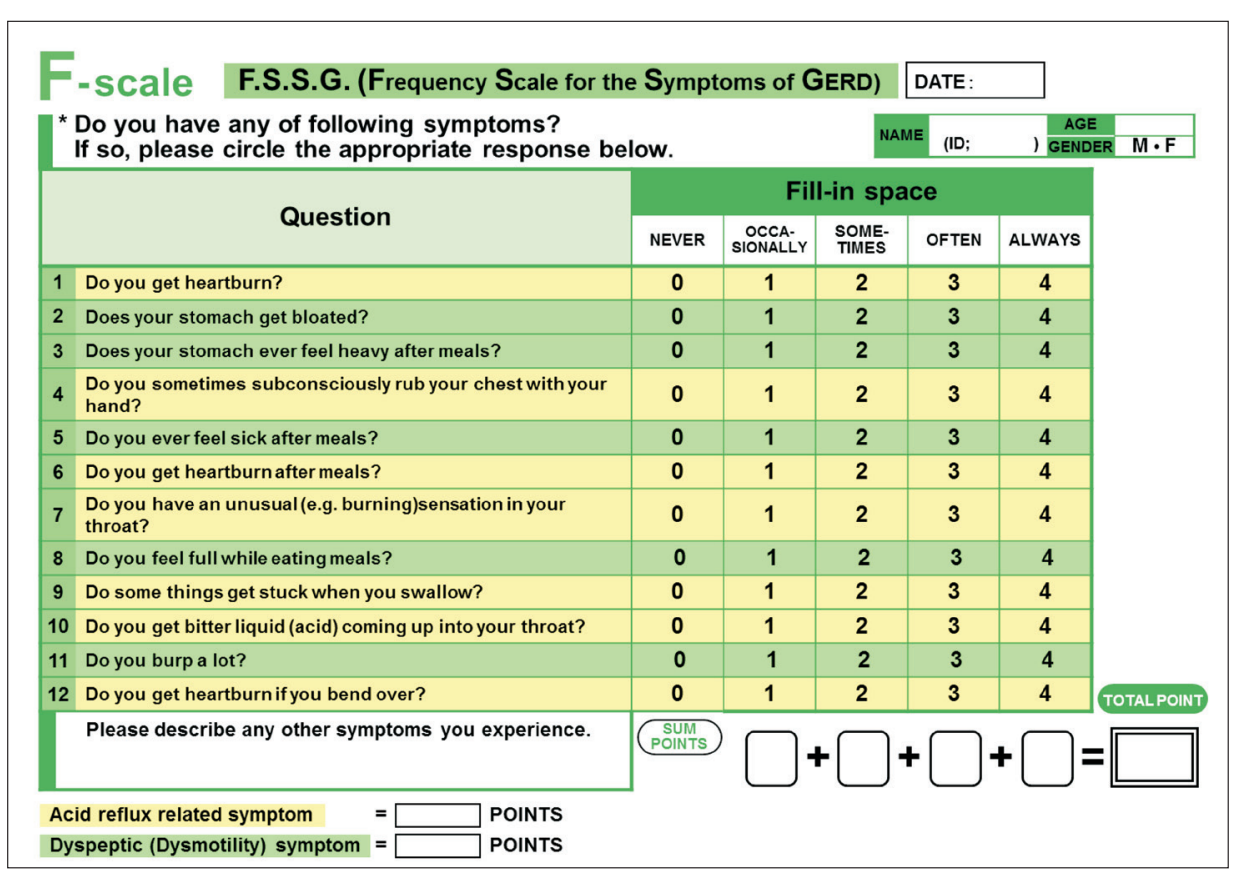

Figure 1. Frequency scale for symptoms of gastroesophageal reflux disease (GERD). Adapted from Kusano et al with permission. 
positive symptom was defined as a symptom for which the subject evaluated the frequency with a score of $\geq 2$ (sometimes, often, or always). The 12 questions were "Do you get heartburn?," "Does your stomach get bloated?," "Does your stomach ever feel heavy after meals?," "Do you sometimes subconsciously rub your chest with your hand?," "Do you ever feel sick after meals?," "Do you get heartburn after meals?," "Do you have an unusual (eg, burning) sensation in your throat?," "Do you feel full while eating meals?," "Do some things get stuck when you swallow?," "Do you feel a bitter liquid (acid) coming up into your throat?," "Do you burp a lot?," and "Do you get heartburn if you bend over?"

\section{Statistical Methods}

Statistical evaluation was carried out using the $\chi^{2}$ test and $t$ test (version 22; SPSS, Tokyo, Japan).

\section{Results}

Among the 581 young healthy adults who correctly completed the questionnaires, 298 subjects with no $H$. pylori infection and no abnormal findings on upper gastrointestinal endoscopy were enrolled in the present study as indicated in Figure 2. The subjects included 163 males (age, $23.7 \pm 1.7$ years) and 135 females (age, $23.1 \pm 1.5$ years). The demographic data of the subjects are presented in Table 1 . All the subjects enrolled in the present study did not take any medicine, including non-steroidal anti-inflammatory drugs during the 1 month before endoscopy. There were no significant differences in terms of age, body mass index of $<25 \mathrm{~kg} / \mathrm{m}^{2}$, smoking, or alcohol drinking of more than twice a week.

Overall, the females (69 of 163, 55.6\%) complained of up-

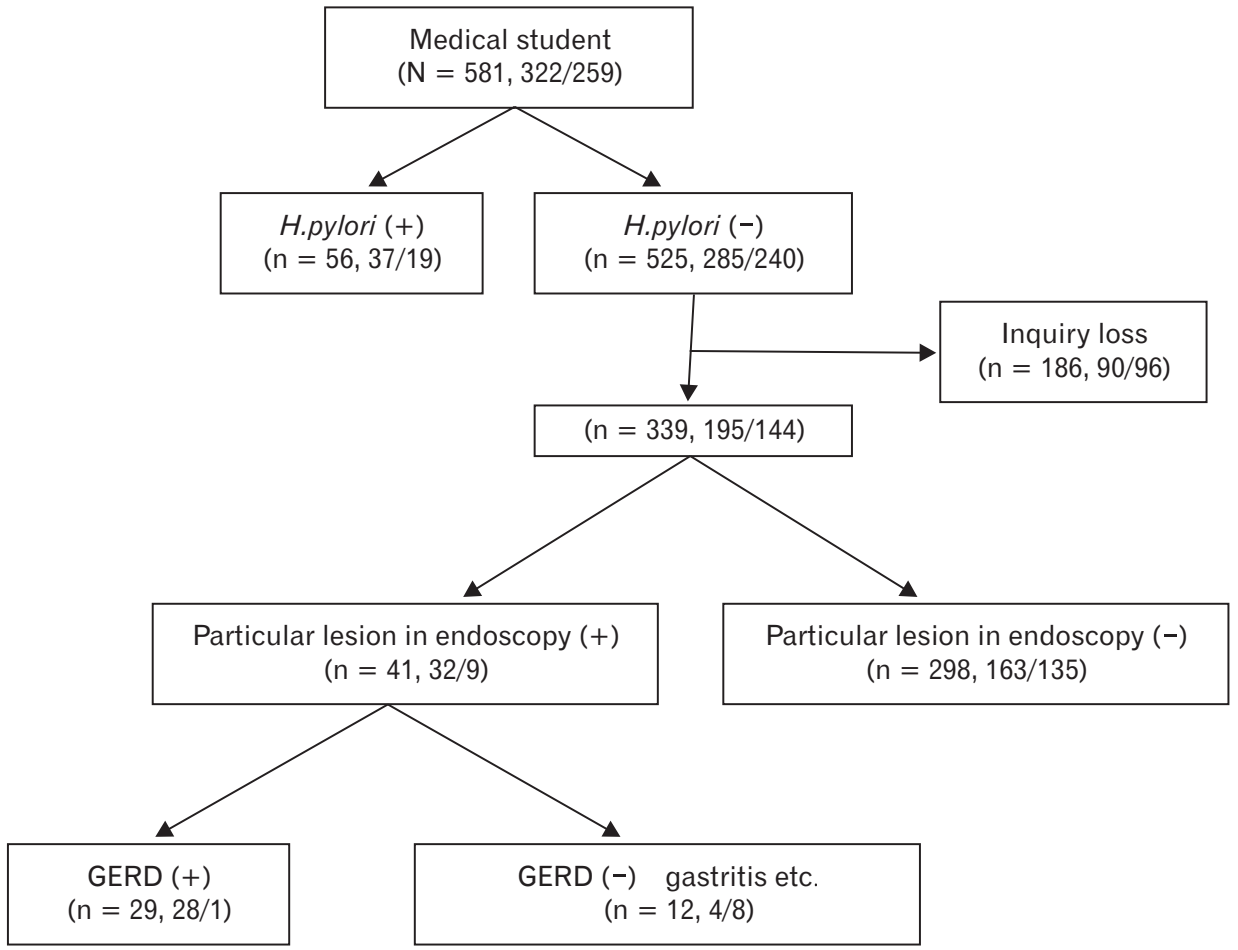

Figure 2. Flowchart for selected 298 subjects enrolled in the present study. H. pylori, Helicobacter pylori; GERD, gastroesophageal reflux disease.

Table 1. Characteristics of the Healthy Young Subjects with No Helicobacter pylori Infection and No Abnormalities on Upper Gastrointestinal Endoscopy

\begin{tabular}{lccc}
\hline & $\begin{array}{c}\text { Males } \\
(\mathrm{n}=163)\end{array}$ & $\begin{array}{c}\text { Females } \\
(\mathrm{n}=135)\end{array}$ & $P$-value \\
\hline Age $(\mathrm{yr})$ & $23.7 \pm 1.71$ & $23.1 \pm 1.53$ & 0.249 \\
Body mass index $\left(\mathrm{kg} / \mathrm{m}^{2}\right)<25$ & $157(96.3 \%)$ & $125(92.6 \%)$ & 0.058 \\
Smoking & $7(4.3 \%)$ & $1(0.7 \%)$ & 0.780 \\
Alcohol drinking & $141(86.5 \%)$ & $116(85.9 \%)$ & \\
\hline
\end{tabular}

Values are presented as mean \pm standard deviation. 
Table 2. Difference in Gastrointestinal Symptoms as Evaluated by the Frequency Scale for the Symptoms of Gastroesophageal Reflux Disease Between Females and Males with No Particular Lesions on Upper Gastrointestinal Endoscopic Examination

\begin{tabular}{|c|c|c|c|c|c|}
\hline & $\begin{array}{c}\text { Males } \\
(\mathrm{n}=163)\end{array}$ & $\begin{array}{l}\text { Females } \\
(\mathrm{n}=135)\end{array}$ & OR & $P$-value & $95 \% \mathrm{CI}$ \\
\hline Heartburn & $19(11.7 \%)$ & $22(16.3 \%)$ & 1.48 & 0.247 & $0.76-2.86$ \\
\hline Stomach get bloated & $21(12.9 \%)$ & $39(28.9 \%)$ & 2.75 & 0.001 & $1.52-4.96$ \\
\hline Stomach feel heavy after meals & $31(19.0 \%)$ & $40(29.6 \%)$ & 1.79 & 0.032 & $1.05-3.07$ \\
\hline Subconsciously rub your chest with your hand & $6(3.7 \%)$ & $20(14.8 \%)$ & 4.55 & 0.001 & $1.77-11.69$ \\
\hline Feel sick after meals & $17(10.4 \%)$ & $19(14.1 \%)$ & 1.41 & 0.337 & $0.70-2.83$ \\
\hline Heartburn after meals & $14(8.6 \%)$ & $13(9.6 \%)$ & 1.13 & 0.755 & $0.51-2.50$ \\
\hline Unusual sensation in your throat & $5(3.1 \%)$ & $6(4.4 \%)$ & 1.47 & 0.531 & $0.44-4.93$ \\
\hline Feel full while eating meals & $12(7.4 \%)$ & $23(17.0 \%)$ & 2.58 & 0.010 & $1.23-5.41$ \\
\hline Get stuck when you swallow & $4(2.5)$ & $4(3.0 \%)$ & 1.21 & 0.787 & $0.30-4.95$ \\
\hline Bitter liquid coming up into your throat & $13(8.0 \%)$ & $10(7.4 \%)$ & 0.92 & 0.855 & $0.39-2.18$ \\
\hline Burp a lot & $22(13.5 \%)$ & $16(11.9 \%)$ & 0.86 & 0.672 & $0.43-1.72$ \\
\hline Heartburn if you bend over & $1(0.6 \%)$ & $4(3.0 \%)$ & 4.94 & 0.117 & $0.55-44.79$ \\
\hline Positive of any gastrointestinal symptoms in FSSG & $69(42.3 \%)$ & $75(55.6 \%)$ & 1.70 & 0.023 & $1.08-2.70$ \\
\hline
\end{tabular}

FSSG, frequency scale for the symptoms of gastroesophageal reflux disease.

A positive symptom was defined as a symptom for which the subject evaluated the frequency with a score of $\geq 2$ (sometimes, often, or always).

Table 3. Comparison of Acid Reflux Symptom Scores and Dysmotility Symptom Scores Between Females and Males with No Particular Lesion on Endoscopic Examination

\begin{tabular}{lccc}
\hline & $\begin{array}{c}\text { Males } \\
(\mathrm{n}=69)\end{array}$ & $\begin{array}{c}\text { Females } \\
(\mathrm{n}=75)\end{array}$ & $P$-value \\
\hline Acid reflux score & $3.54 \pm 3.05$ & $3.92 \pm 3.27$ & 0.469 \\
Dysmotility score & $4.93 \pm 2.35$ & $5.84 \pm 2.75$ & 0.035 \\
\hline
\end{tabular}

Values are presented as mean \pm standard deviation.

per gastrointestinal symptoms more frequently than did the males (75 of 135, 42.3\%; $P<0.05$ ). The frequency of the following symptoms on the FSSG was higher in females than males (Table 2): bloated stomach, heavy feeling in the stomach after meals, subconscious rubbing of the chest with the hand, and feeling of fullness while eating meals. None of the other symptoms were different between the 2 sexes (ie, heartburn, feeling sick after meals, heartburn after meals, an unusual sensation in the throat, a feeling of stuckness when swallowing, bitter liquid coming up into the throat, frequent burping, and heartburn when bending over). Among the subjects who complained of upper gastrointestinal symptoms on the FSSG, the females complained more often than the males of dysmotility symptoms $(P<0.05)$, but not of reflux symptoms (Table 3 ).

Endoscopic examination revealed that 29 out of 339 subjects (8.6\%) had endoscopic reflux esophagitis, with 28 of 195 (14.4\%) males and 1 of $144(0.7 \%)$ females of grade A esophagitis. The endoscopic reflux esophagitis in the 28 males was grade $\mathrm{A}$ in 24 subjects and grade B in 4. The upper gastrointestinal symptoms on the FSSG were compared between the males with and without endoscopic reflux esophagitis (Table 4). Only one symptom, frequent burping, was more often observed in the males with endoscopic reflux esophagitis $(P=0.014)$. The other symptoms, including reflux symptoms and dysmotility symptoms, did not differ between the males with and without endoscopic reflux esophagitis.

Subjects with $H$. pylori infection were 56 out of 581 (9.6\%), and 32 subjects (21 males and 11 females) correctly completed the FSSG questionnaires. Among the subjects with $H$. pylori infection, neither acid reflux score nor dysmotility score was different between the males and females.

\section{Discussion}

In this study, young healthy females obtained higher total FSSG scores for 4 symptoms (bloated stomach, heavy feeling in the stomach after meals, subconscious rubbing of the chest with the hand, and feeling of fullness while eating meals) compared with young healthy males, indicating that young healthy females more frequently experience upper gastrointestinal symptoms. In 2013, the Ministry of Health, Labor and Welfare of Japan reported that females were more likely than males to have health-related complaints regardless of the generation. ${ }^{1}$ Several studies have suggested that among patients with $\mathrm{FD}$, females complain more severe symptoms than do males. ${ }^{4}$ The present study might be the first to compare upper gastrointestinal symptoms between relatively large numbers 
Table 4. Difference in Gastrointestinal Symptoms Between Males with and Without Endoscopic Reflux Esophagitis as Evaluated by the Frequency Scale for the Symptoms of Gastroesophageal Reflux Disease

\begin{tabular}{|c|c|c|c|c|c|}
\hline & $\begin{array}{l}\mathrm{RE}(+) \\
(\mathrm{n}=28)\end{array}$ & $\begin{array}{l}\mathrm{RE}(-) \\
(\mathrm{n}=163)\end{array}$ & OR & $P$-value & $95 \% \mathrm{CI}$ \\
\hline Heartburn & $5(17.6 \%)$ & $19(11.7 \%)$ & 1.64 & 0.362 & $0.56-4.85$ \\
\hline Stomach get bloated & $5(17.6 \%)$ & $21(12.9 \%)$ & 1.47 & 0.479 & $0.50-4.29$ \\
\hline Stomach feel heavy after meals & $5(17.6 \%)$ & $31(19.0 \%)$ & 0.93 & 0.885 & $0.33-2.63$ \\
\hline Subconsciously rub your chest with your hand & $2(7.1 \%)$ & $6(3.7 \%)$ & 2.01 & 0.399 & $0.39-10.52$ \\
\hline Feel sick after meals & $2(7.1 \%)$ & $17(11.6 \%)$ & 0.66 & 0.592 & $0.14-3.03$ \\
\hline Heartburn after meals & $2(7.1 \%)$ & $14(8.6 \%)$ & 0.82 & 0.799 & $0.18-3.82$ \\
\hline Unusual sensation in your throat & $2(7.1 \%)$ & $5(3.1 \%)$ & 2.43 & 0.290 & $0.45-13.19$ \\
\hline Feel full while eating meals & $2(7.1 \%)$ & $12(7.4 \%)$ & 0.97 & 0.967 & $0.21-4.58$ \\
\hline Get stuck when you swallow & $1(3.6 \%)$ & $4(2.6 \%)$ & 1.47 & 0.733 & $0.16-13.68$ \\
\hline Bitter liquid coming up into your throat & $5(17.6 \%)$ & $13(8.0 \%)$ & 2.51 & 0.099 & $0.82-7.70$ \\
\hline Burp a lot & $9(32.1 \%)$ & $22(13.5 \%)$ & 3.04 & 0.014 & $1.22-7.55$ \\
\hline Heartburn if you bend over & $0(0 \%)$ & $1(0.6 \%)$ & 0 & 0.679 & $0.98-1.01$ \\
\hline Positive of any gastrointestinal symptoms in FSSG & $16(57.1 \%)$ & $69(42.3 \%)$ & 1.82 & 0.145 & $0.81-4.09$ \\
\hline
\end{tabular}

RE, reflux esophagitis; FSSG, frequency scale for the symptoms of gastroesophageal reflux disease.

A positive symptom was defined as a symptom for which the subject evaluated the frequency with a score of $\geq 2$ (sometimes, often, or always).

of young males and females with no abnormal gastrointestinal endoscopic findings or $H$. pylori infection. The results might help in the development of diagnostic and treatment methods for upper gastrointestinal symptoms.

Among the young healthy $H$. pylori negative subjects of this study, endoscopic reflux esophagitis had developed in 29 out of 339 subjects (8.6\%): 28 of 195 males (14.4\%) and 1 of 144 females $(0.7 \%)$. While the incidence of reflux esophagitis without $H$. pylori infection was almost equivalent to the previous studied, ${ }^{9,10}$ the main factors associated with the relatively high incidence of esophagitis in males are not clear. Drinking alcohol might be related to the development of esophagitis in young males and warrants further examination. The present study revealed that the FSSG scores among the males with endoscopic reflux esophagitis were not different from those of healthy males, suggesting that the males with reflux esophagitis did not experience reflux symptoms. The reason for this discrepancy between the symptoms and the endoscopic findings is unclear, although several studies in Japan have reported such a discrepancy. ${ }^{10,11}$ Additionally, our previous studies showed that some patients with reflux esophagitis could not be diagnosed by the FSSG. ${ }^{12-15}$

The detailed analysis in the present study revealed that the young females complained more frequently than the males of dysmotility symptoms, but not reflux symptoms. The high frequency of dyspeptic symptoms in the young healthy females might be related to the high prevalence of FD in Japanese women. A previous study reported that the prevalence of FD in Japan was $11 \%$ in males and $26 \%$ in females. ${ }^{16}$ Other studies reported that Japanese female subjects had dyspepsia symptoms at health check-ups more commonly than did males and that postprandial distress syndrome was dominant over epigastric pain syndrome, ${ }^{4}$ whereas the dominance of postprandial distress syndrome varied among generations in the United States and countries such as Sweden, Italy, and China. ${ }^{16}$

In conclusion, the present study indicates that young healthy females in Japan complain of upper gastrointestinal symptoms more frequently than do males, and that this difference may be related to the higher incidence of FD in young Japanese females.

\section{Financial support: None.}

\section{Conflicts of interest: None.}

Author contributions: Hiroharu Kawakubo summarized the data; Megumi Hara contributed statistical analysis; and Yuichiro Tanaka, Nanae Tsuruoka, Koji Yamamoto, Hidenori Hidaka, Yasuhisa Sakata, Ryo Shimoda, Ryuichi Iwakiri, Motoyasu Kusano, and Kazuma Fujimoto collected the data.

\section{References}

1. Itoh $\mathrm{M}$, Ibe $\mathrm{T}$, Umeda $\mathrm{K}$, et al. [Health status and receivineg medical treatment.] J Health Welf Stat 2014;61:87-94. [Japanese] 
2. Olafsdottir LB, Gudjonsson H, Jonsdottir HH, Thjodleifsson B. Natural history of functional dyspepsia: a 10-year population-based study. Digestion 2010;81:53-61.

3. Okumura T, Tanno S, Ohhira M, Tanno S. Prevalence of functional dyspepsia in an outpatient clinic with primary care physicians in Japan. J Gastroenterol 2010;45:187-194.

4. Schlemper RJ, van der Werf SD, Vandenbroucke JP, Biemond I, Lamers CB. Peptic ulcer, non-ulcer dyspepsia and irritable bowel syndrome in The Netherlands and Japan. Scand J Gastroenterol 1993;200(suppl):33-41.

5. Kiyota K. [Epidemiology of non-ulcer dyspepsia (NUD) in Japan.] Nihon Shokakibyo Gakkai Zasshi 1992;89:1973-1981. [Japanese]

6. Miwa H. Why dyspepsia can occur without organic disease: pathogenesis and management of functional dyspepsia. J Gastroenterol 2012;47:862871.

7. Kusano M, Shimoyama Y, Sugimoto S, et al. Development and evaluation of FSSG: frequency scale for the symptoms of GERD. J Gastroenterol 2004;39:888-891.

8. Armstrong D, Bennett JR, Blum AL, et al. The endoscopic assessment of esophagitis: a progress report on observer agreement. Gastroenterology 1996;111:85-92.

9. Takasima T, Iwakiri R, Sakata Y, et al. Endoscopic reflux esophagitis and Helicobacter pylori infection in young healthy Japanese volunteers. Di- gestion 2012;86:55-58.

10. Fujiwara Y, Arakawa T. Epidemiology and clinical characteristics of GERD in the Japanese population. J Gastroenterol 2009;44:518-534.

11. Okamoto K, Iwakiri R, Mori M, et al. Clinical symptoms in endoscopic reflux esophagitis: evaluation in 8031 adult subjects. Dig Dis Sci 2003; 48:2237-2241.

12. Eguchi H, Eguchi Y, Fujiwara M, et al. Arm span-height difference is correlated with gastroesophageal reflux symptoms in aged Japanese subjects. J Clin Biochem Nutr 2013;52:89-93.

13. Danjo A, Yamaguchi K, Fujimoto K, et al. Comparison of endoscopic findings with symptom assessment systems (FSSG and QUEST) for gastroesophageal reflux disease in Japanese centres. J Gastroenterol Hepatol 2009;24:633-638.

14. Komatsu-Tanaka M, Iwakiri R, Fujimoto K, et al. Clinical symptoms of FSSG in gastroesophageal reflux disease are critical for PPI treatment: Japanese multi-centers with 185 patients. Dig Endosc 2012;24:407-411.

15. Akutagawa K, Iwakiri R, Hara M, et al. Risk factors for low response to proton-pump inhibitor treatment in reflux esophagitis and non-erosive reflux disease evaluated by the frequency scale for the symptoms of gastroesophageal reflux disease. Esophagus 2015;12:225-232.

16. Oshima T, Miwa H. Epidemiology of functional gastrointestinal disorders in Japan and in the world. J Neurogastroenterol Motil 2015;21:320329 